\title{
Prevalence of cigarette smoking in the Rafsanjan urban population
}

\author{
E.N. Ali ${ }^{1}$ and A. Jafar ${ }^{1}$
}

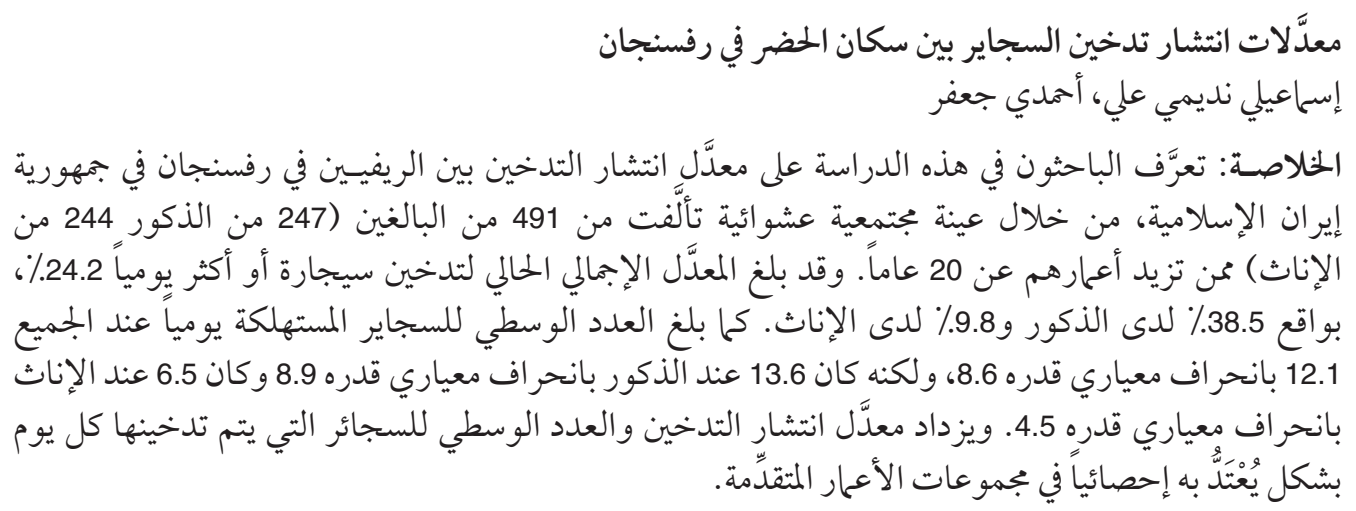

ABSTRACT This study determined the smoking rate in the urban population of Rafsanjan, Islamic Republic of Iran, in a random community sample of 491 adults (247 males and 244 females) aged $>20$ years. The overall prevalence of current smoking (1+ cigarettes per day) was $24.2 \% ; 38.5 \%$ in males and $9.8 \%$ in females. The mean number of cigarettes consumed per day was 12.1 [standard deviation (SD 8.6)]; 13.6 (SD 8.9) in men and 6.5 (SD 4.5) in women. The prevalence and mean number of cigarettes smoked per day increased significantly in older age groups.

\section{Prévalence de la consommation de cigarettes dans la population urbaine de Rafsanjan}

RÉSUMÉ Cette étude a déterminé le taux de tabagisme dans la population urbaine de Rafsanjan (République islamique d'Iran), sur la base d'un échantillon aléatoire de la population composé de 491 adultes (247 hommes et 244 femmes) âgés de plus de 20 ans. La prévalence globale de tabagisme au moment de l'étude ( 1 cigarette au moins par jour) était de $24,2 \% ; 38,5 \%$ chez les hommes et 9,8 \% chez les femmes. Le nombre moyen de cigarettes consommées par jour était de 12,1 [écart type (E.T. 8,6)], 13,6 (E.T. 8,9) chez les hommes et 6,5 (E.T. 4,5) chez les femmes. La prévalence et le nombre moyen de cigarettes fumées par jour augmentaient significativement dans les groupes plus âgés.

${ }^{1}$ Department of Internal Medicine, Medical School, Rafsanjan University of Medical Sciences and Health Services, Rafsanjan, Islamic Republic of Iran (Correspondence to E.N.Ali: dr_nadimi@yahoo.co.uk). Received: 26/12/04; accepted: 05/02/07 


\section{Introduction}

Cigarette smoking is the leading preventable cause of death and morbidity worldwide [1]. In the United States of America (USA), as elsewhere in the developed world, the estimated rate of smoking in men has been falling: from $55 \%$ in 1955 to about $25 \%$ in 2001 $[2,3]$. In developing countries, however, the rate of smoking continues to rise [4]. More alarming is the evidence that smoking rates are increasing among children and women and, unless effective comprehensive and sustained initiatives are implemented to reduce smoking, the prevalence of smoking in women in developed and developing countries has been predicted to rise to $20 \%$ by 2025 [5].

Smoking rates vary across the Asian parts of the Eastern Mediterranean Region. For example, in Oman the overall prevalence of smoking in 2000 was $7 \%(13.4 \%$ in men and $0.5 \%$ in women) [6], while a survey in 2002 recorded the overall prevalence of current smoking in adult males in Karachi, Pakistan as 34\% [7]. Some data are available about the prevalence of smoking in the Islamic Republic of Iran. In the Tehran Lipid and Glucose Study, for example, the global smoking rate in the urban population was $10.6 \%$ (22\% in men and $2.1 \%$ in women) [8]. In Shiraz the prevalence of smoking was reported as $26 \%$ in men and $3.6 \%$ in women [9]. Because this type of research has not been done in the Rafsanjan area the present study was designed to describe the prevalence of smoking in the urban population of this south-east area of the Islamic Republic of Iran.

\section{Methods}

This cross-sectional community study in 2004 was performed on 491 participants over 20 years old in Rafsanjan (247 men and
244 women). The population of the urban area of Rafsanjan was about 112000 . The expected prevalence of smoking according to a pilot study was about $30 \%$, so with desired precision $5 \%$ and with confidence interval $95 \%$ the sample size was estimated to be 322 participants. For a safety margin due to the type of sampling and design effect, a final sample of about 500 participants was enrolled.

The sample was chosen using a randomized cluster method. Clusters were defined previously by the local health organization; 28 clusters were selected, each cluster containing 58 families. Families were randomly selected from the clusters, but if there were any problems contacting a family or a member refused to participate, the next neighbours on the right side of that family were selected and if that was unsuccessful the family on the left side was selected. About 9 family members refused to participate and were replaced with another family as described above.

Participants were requested to complete a questionnaire about demographic data, the number of cigarettes smoked and the duration of cigarette smoking. Those who smoked 7+ cigarettes per week were considered current smokers. The interviews were carried out by 2 general physicians and filled questionnaires were randomly checked by the author.

For data analysis SPSS, version 11 was used. For nominal variables the chi-squared and Fisher exact tests and for continuous variables the independent $t$-test and 1-way ANOVA were used.

\section{Results}

The mean age of participants was 38.4 (13.1) years; $50.3 \%$ male and $49.7 \%$ female. The overall rate of smoking was $24.2 \%$ [ $95 \%$

المجلة الصحية لشرق المتوسط، منظمة الصحة العالمية، المجلد الخنامس عشر، العدد ع، 9 +. 
confidence interval (CI) $20.6 \%-28.3 \%]$. The rate was $38.5 \%(32.4 \%-44.9 \%)$ and $9.8 \%(6.5 \%-14.5 \%)$ for men and women respectively and the sex difference in smoking prevalence was significant (relative risk $=2.46, P=0.001$ ).

The mean number of cigarettes consumed per day by smokers was 12.1 [standard deviation (SD 8.6)], greater in men 13.6 (SD 8.9) than women 6.5 (SD 4.5). The difference between the 2 sexes in the mean number of cigarettes smoked per day was significant $(P=0.001)$.

The mean duration of smoking was 14.2 (SD 9.2) years for men and 14.6 (SD 9.2) years for women. The proportion of heavy smokers ( $>20$ cigarettes per day) was $1.2 \%$ of the total sample and about $5 \%$ of current smokers. No woman reported being a heavy smoker. The prevalence of smoking in the sample increased with increasing age from $19.3 \%$ in the age group $20-29$ years to $32.0 \%$ at ages $40-49$ years before declining to $19.0 \%$ at age $\geq 60$ years $(P=0.001)$ (Table 1). The mean number of cigarettes smoked rose with age from 9.6 per day in age group 20-29 years to 15.3 in the age group $\geq 60$ years $(P=0.001)$.

\section{Discussion}

Cigarette smoking is an important social problem. Although the role of smoking as a risk factor in many diseases has been clearly established, the smoking rate in developing countries continues to rise. In the USA the smoking rate in 1955 was about $55 \%$ in men and $34 \%$ in women and currently this rate is about $25 \%$ and $21 \%$ respectively $[1,3]$. In China it was reported in 1995 that $63 \%$ of men and $3.8 \%$ of women were current smokers [10].

In the Eastern Mediterranean Region the prevalence of cigarette smoking varies among different countries. For example in a 2004 report from Kuwait, the rate of smoking was $37 \%$ among married men and $0.5 \%$ among married women [6]. In Saudi Arabia, the 1994 smoking rate was $40.0 \%$ for males and $8.2 \%$ for women [7]. In the Islamic Republic of Iran previous studies in Tehran found the smoking rate was $22 \%$ in men and $2.1 \%$ in women [8] and in Shiraz these values were $26 \%$ and $3.6 \%$ respectively [9]. Rafsanjan is an urban area of the south-east of the Islamic Republic of Iran, and the generalization of our data to other parts of the country is uncertain. However our data showed an overall self-reported smoking rate of $24.2 \%$ (38.5\% in men and $9.8 \%$ in women).

This study shows that despite the increasing awareness of the health problems due to tobacco use, smoking is still common and the prevalence of smoking in women was higher than previous studies in the

\begin{tabular}{lcccccccrr}
\hline \multicolumn{1}{l}{ Table 1 Smoking prevalence by sex and age } \\
\hline $\begin{array}{l}\text { Age } \\
\text { (years) }\end{array}$ & $\begin{array}{c}\text { No. } \\
\text { sampled }\end{array}$ & $\begin{array}{c}\text { Total } \\
\text { No. of } \\
\text { smokers }\end{array}$ & $\%$ & $\begin{array}{c}\text { No. } \\
\text { sampled }\end{array}$ & $\begin{array}{c}\text { Males } \\
\text { No. of } \\
\text { smokers }\end{array}$ & $\%$ & $\begin{array}{c}\text { No. } \\
\text { sampled }\end{array}$ & $\begin{array}{c}\text { No. of } \\
\text { smokers }\end{array}$ & $\%$ \\
\hline $20-29$ & 140 & 27 & 19.3 & 69 & 21 & 30.4 & 71 & 6 & 8.5 \\
$30-39$ & 157 & 39 & 24.8 & 78 & 34 & 43.6 & 79 & 5 & 6.3 \\
$40-49$ & 100 & 32 & 32.0 & 49 & 25 & 51.0 & 51 & 7 & 13.7 \\
$50-59$ & 52 & 13 & 25.0 & 29 & 9 & 31.0 & 23 & 4 & 17.4 \\
$\geq 60$ & 42 & 8 & 19.0 & 22 & 6 & 27.3 & 20 & 2 & 10.0 \\
Total & 491 & 119 & 24.2 & 247 & 95 & 38.5 & 244 & 24 & 9.8 \\
\hline
\end{tabular}


Islamic Republic of Iran. The health effects of smoking for women are more serious than for men because exposure to smoking had additional hazards in pregnancy and sex-specific cancers such as cancer of the cervix [6]. Anti-tobacco strategies should be vigorously implemented to prevent the health consequences of smoking, and the motivations for smoking cessation should be taken into consideration in planning a health education strategy.

\section{References}

1. Braunwald E, Zipes DP, Libby P, eds. Braunwald's heart disease, 7th ed. Volume 1. Philadelphia, WB Saunders, 2005:1065.

2. Cigarette smoking among adults-United States 1997. Morbidity and mortality weekly report, 1999, 48:993-6.

3. Cigarette smoking among adults-United States 2001. Morbidity and mortality weekly report, 2003, 24:953-6.

4. World health report 1999. Making a difference. Geneva, World Health Organization, 1999.

5. Mackay J, Amos A. Women and tobacco. Respirology, 2003, 8(2):123-30.

6. Al Riyami AA, Afifi M. Smoking in Oman: prevalence and characteristics of smok- ers. Eastern Mediterranean health journal, 2004, 10(4/5):600-9.

7. Saeed AA, Khoja TA, Khan SB. Smoking behaviour and attitude among adult Saudi nationals in Riyadh City, Saudi Arabia. Tobacco control, 1996, 5(3):215-9.

8. Azizi $\mathrm{F}$ et al. Cardiovascular risk factors in an Iranian urban population: Tehran Lipid and Glucose Study (phase 1). Sozial- und Präventivmedizin, 2002, 47:408-26.

9. Ahmadi $\mathrm{J}$ et al. Prevalence of cigarette smoking in Iran. Psychological reports, 2001, 89(2):339-41.

10. Gong YL et al. Cigarette smoking in China: prevalence, characteristics and attitudes in Minhang district. Journal of the American Medical Association, 1995, 274(15):1232-4. 